\title{
A Charge Controller Techniques for Solar PV System
}

\author{
P. Maithili, K. Kanakaraj
}

\begin{abstract}
In rural electrification the PV system plays an important role. Due to high costs in individual $P V$ battery structures and large number of available lunar charge controllers it is important to select a suitable controller for each application. The overall system power flow is regulated by the special control unit is that charge controllers. This solar battery charger has normalize the potential difference and current flows in house-hold applications, multiple energy sources and converters which converts DC electric charge into AC. Several topologies dominate the world market. The solar charge controller has to protect the battery to charge it too much and avoid discharging with bottom value by using the low voltage and high voltage disconnection ( $L V D \& H V D)$. In addition to this a charge regulator should have to monitoring the battery status. The state of charge calculation of this solar PV charge controller is good and it provides better battery management. The charge controller of solar PV system consists of shunt and series charge controller. A new technology based solar PV system controller is discussed in this paper. This controller is developed using MATLAB/SIMULINK.
\end{abstract}

Key words: SOC (State of Charge), Charge Controller, Battery Charging and Discharging.

\section{INTRODUCTION}

The leading causes of industrial air pollution is electrical power creation. The electrical power is mostly created by nuclear and other non-renewable/ conventional sources based power plants. Turn out electricity by the above mentioned resources creates several constraint on our atmosphere, contaminating water, midair and terrestrial areas. Electrical quantity generation by the non-conventional energy resources would have minor influence on to the environment. The way to generate electrical quantity from renewable energy sources without production $\mathrm{CO} 2$, would be delivering changes to the global. Among all renewable energy resources solar power was acknowledged in power production due to its clearness (No carbon dioxide emission) and cost effectiveness [1].Solar energy changes naturally causing change in output power of converter. The variable output voltage issue is circumvented by using MPPT with Power electronics converters. This method is utilized to achieve flexible output voltage in terms of both frequency and magnitude [2]. The charge controller is provided along with battery charger for receiving maximum amount of power from pv systems. The solar irradiation fluctuates naturally and the electrical power generation from lunar PV is unreliable. Hence, to maximize the solar PV power generation and reduce the charging time of battery the charge controller is used. The over-charging and discharging of

Revised Manuscript Received on 14 August, 2019.

P.Maithili, Assistant Professor, Dept. of EEE, Kumaraguru College of Technology, Coimbatore, Tamilnadu, India.(Email: maithili.p.eee@kct.ac.in)

K.Kanakaraj, Professor, Dept. of EEE, PSG College of Technology, Coimbatore, Tamilnadu, India.(Email: jkr.eee@psgtech.ac.in) battery is also controlled and then battery life time is enhanced. In this paper an efficient charge controller is developed with longer life expectancy. To improve the battery charging efficiency, to reduce the power consumption by the solar cells/array and to meet the electricity demand a new algorithm founded for the implementation of photo voltaic charge controller is developed and discussed in this paper.

Many more charge controllers methods are available now a days. They are series, by-pass, Pulse Width Modulated regulators and charge controller with MPPT. In shunt regulator the Photovoltaic array is short circuited by the transistor (Switch element) when the battery reaches the set voltage and blocking diodes are to stop the reversal flow of current to the array. It is a single stage controller which means the regulation either ON or OFF. This shunt controller is used in smaller solar PV arrays. The series controller monitoring the battery voltage, when it reaches a set voltage this regulator open circuit the PV array from battery. The switch element of this regulator is provide the path in between battery and array with series combination. In positive and negative ground systems whereas shunt regulator is negative grounded system is uses the above mentioned charge regulator type. If the regulator open circuits the PV array, its run without heat generation because of this reason this series regulator can be used for larger PV systems. The battery is protected from over charging or over discharging irrespective of the operating temperature, system design and load profile changes using a battery charger. The power consumption of solar array, improvement of battery charging and demand requirement based system capacity was discussed in [3]. Other features also included in solar charge controller, such as alarms, compensating operating temperature and a new technology based algorithms. The ability of a charge controller is enhanced by the above mentioned additional features. These controllers are enhanced to maximize the capacity, maintain the dynamic changes of energy from solar PV array and increases the life span of battery.

\section{PROPOSED SYSTEM}

This paper presents a controller which controls the reverse current flow, helps to protect battery when the battery voltage ascents to some level and improve the battery lifecycle, reduce the system maintenance effectively.This proposed charge controller contains both shunt and series regulator[4][5]. The block diagram of solar charge controller connection is shown in fig.1.

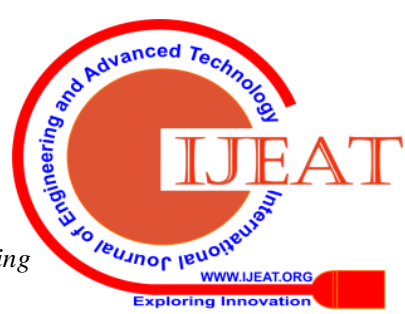




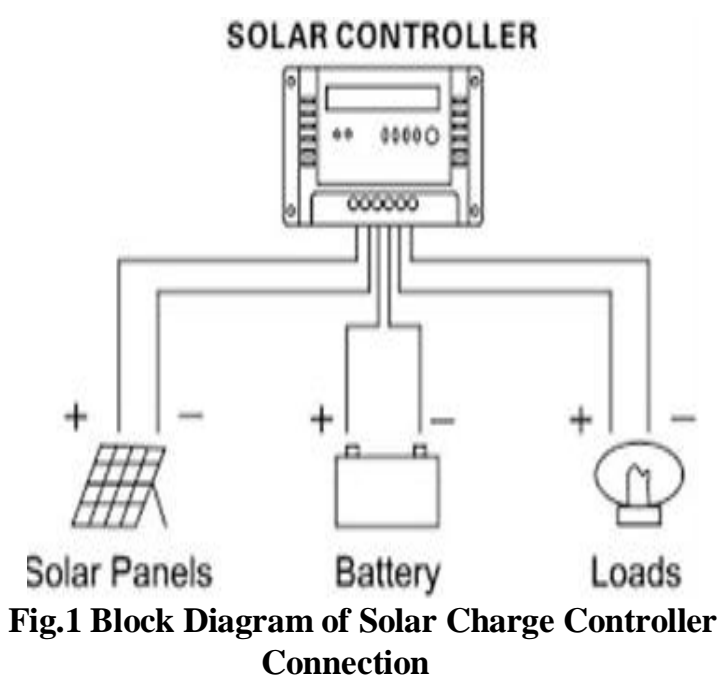

This One and Two stage controllers are most basic form of charge controller and Work by simply directing current fully on/off (1 stage) or reducing current in two steps (2 stage). It utilize relays to act as a simple disconnect switch. In series regulators, the main switching component is in conduction state or blocking state by closing it fully or by opening it fully. In an idyllic circumstances, the system has better performance without losing any amount of power. The potential difference and current value of main component in the regulator becomes zero at any cost. In these controller, the main component present in series with system is regulates the charging current. Initially the relays are acted as a main component of the system. In the beginning the charge controllers used the relay circuit for better operation. Now a days the charge regulator utilizes the power semiconductor devices as switching element (voltage controlled device MOSFET). The voltage stress of the main component of the switch is tiny when compared with parallel regulators. Parallel or shunt controller employs the PV modules physical mechanical and electrical characteristics[6].The proposed charge controller which contains both series and shunt regulator and it has been developed using MATLAB/SIMULINK software. The ability of the battery to adapt dynamic changes of the solar PV generated power. The block diagram of the entire system is shown in fig. 2 .

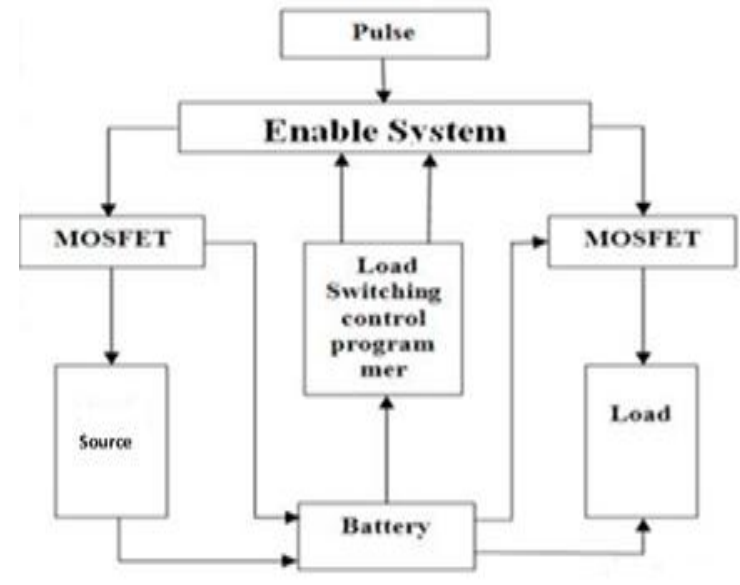

Fig.2Block Diagram of the System

The state of charge calculation and operating temperature is taken as a input into this system. The load switches control programmer generates the pulses to the switch element such as relays, transistors or MOSFET. In this proposed system MOSFET is used as a switching element. The enable system is acting as a key controller for entire system. It will discharge the battery by enabling load side switch and also it makes the battery to charge from solar panel by enabling the source side switch. Here, the main component of the system is linked in both input/source sideways and also load sideways. It enhances the battery operation by using both shunt series regulators.

\section{DEVELOPMENT OF CONTROLLER}

This proposed solar charge controller is developed based on the block diagram in Fig. 2.

In PV systems, for battery charging usage series charge regulator is used and shunt regulator is used for battery discharging. MOSFET1 is connected in source side and MOSFET2 is connected in load side of the system. The circuit diagram of the charge controller is shown in Fig.3

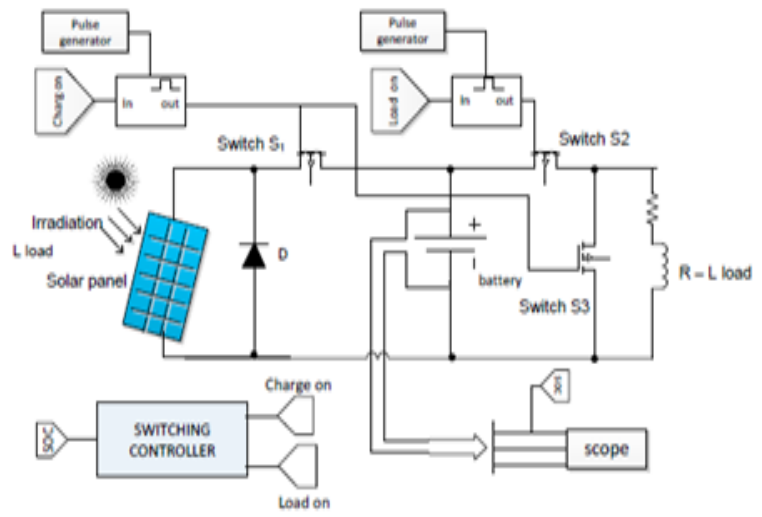
Fig.3Circuit Diagram of the Proposed Charge
Controller

The charge on and enable system is connected to the both MOSFET1\&2 switches. The MOSFET1 will conduct when SOC of battery reaches $80 \%$. Now, the battery enters into battery discharging mode

[charge on $]=0,[$ Load on] $=1$. The MOSFET2 switch will conduct when the SOC of battery reaches $20 \%$. Now, the battery operates in charging mode [charging on] $=1$ and $[$ load on $]=0$. An uninterrupted power is supplied to load continuously to meet load demand.

\section{SIMULINK MODEL AND RESULTS}

The controller of the system is developed using MATLAB/SIMULINK software for showcasing the output of the system. The proposed system results are verified with this software outputs. The simulation diagram of proposed charge controller is represented in Fig.4. 


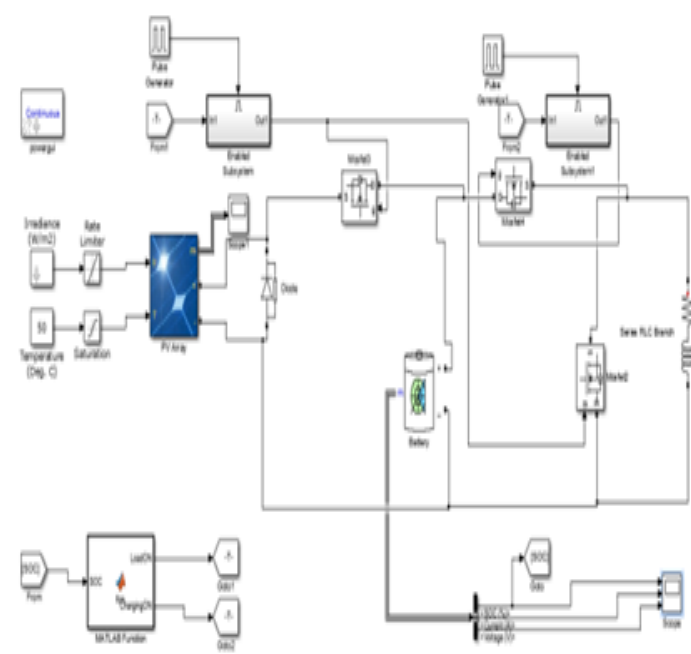

Fig.4 Simulink Model of Proposed charge controller

The Fig.4 shows the Simulink diagram of combined series and shunt regulator. The effectiveness is demonstrated through simulation results. It is seen to be the outputs are better when compared to other methods.

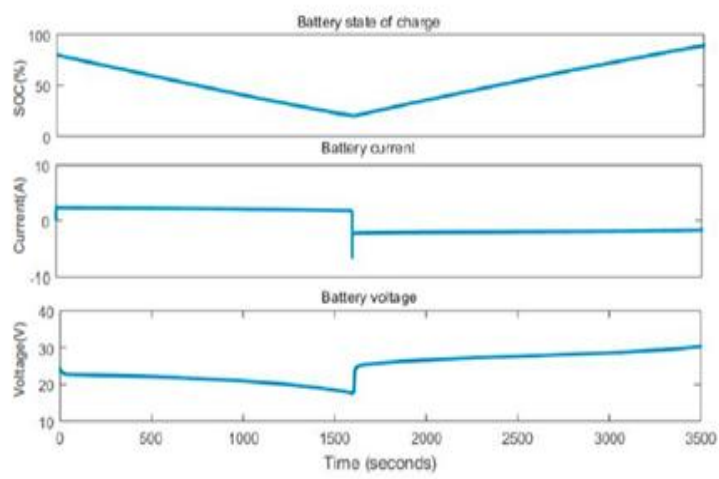

Fig.5 Output Waveforms of combined series and shunt charge controller

The above waveforms illustrate the improved competence and lifespan period of the battery which is used in proposed charge regulators. In this proposed topology, MOSFET1 and 2 is used as a switching element. Hence, the switching losses are minimized by reducing the number of switches into two. The overall system efficiency is improved than the conventional regulators by the design of proposed controller algorithm.

\section{CONCLUSION}

A new algorithm based solar PV battery charger is developed using MATLAB/SIMULINK software. In this paper an improvement on battery performance is tested by considering various parameters under various test conditions. The features of the proposed system are higher charging efficiency for balance-of-system components in PV systems, quick restoring and strong battery at jam-packed capacity. This proposed solar PV charge regulator is reliable and able to meet load demand effectively. The utilization of solar energy is improved by implementing the MPP technique in this controller. This controller take care of battery from over voltage and under voltage conditions. Then life time of battery is extended significantly. The voltage and current stabilization of the system is improved by the proposed charge regulator.

\section{REFERENCES}

1. El-Nashar, A. M. (2010). Desalination with renewable energy-A review. Renewable Energy, in Encyclopedia of Life Support Systems (EOLSS), Developed under the Auspices of the UNESCO, EOLSS Publishers, Oxford, UK. Available from:< http://www. eolss. net>(Retrieved November 21, 2014).

2. Chowdhury, S. R., \& Saha, H. (2010). Maximum power point tracking of partially shaded solar photovoltaic arrays. Solar energy materials and solar cells, 94(9), 1441-1447.

3. Maithili. P.,et al.(2018) three port dc-dc converter for standalone photo-voltaic system. International Journal of Pure and Applied Mathematics 117(8):67-71,DOI: 10.12732/ijpam.v117i8.14.

4. Tamer T.N. Khatib., et al.(2013) A review of photovoltaic systems size optimization techniques. Renewable and Sustainable Energy Reviews 22:454-465, DOI: 10.1016/j.rser.2013.02.023

5. Ingole, J. N., Choudhary, M. A., \& Kanphade, R. D. (2012). PIC based solar charging controller for battery. International Journal of Engineering Science and Technology (IJEST), 4(02), 384-390

6. Osman, S. R., Rahim, N. A., \& Selvaraj, J. (2013, November). Microcontroller based solar battery charging system with MPPT features at low irradiance condition. In 2013 IEEE Conference on Clean Energy and Technology (CEAT) (pp. 437-441). IEEE.

7. Al-Shamma'a, A. A., \& Addoweesh, K. E. (2014) Techno-economic optimization of hybrid power system using genetic algorithm. International journal of energy research, 38(12), 1608-1623. 